\title{
Correspondence
}

\section{Should atropine be routine in children?}

\section{To the Editor:}

In a recent article examining the cardiovascular effects of succinylcholine in 41 children, ages 1-12 years, McAuliffe et al. concluded that the "incidence of bradycardia after succinylcholine ... appears to be less than previously estimated" and offered no specific recommendations regarding the use of atropine before succinylcholine administration. ${ }^{1}$

Several factors may have influenced the incidence of bradycardia observed in this study. The parasympathetic nervous system has been described as "fully functional" at birth, whereas "the sympathetic nervous system does not mature completely until 4-6 months of age". ${ }^{2}$ Therefore, the age group targeted by the study may have been less likely to develop bradycardia than neonates and infants in the first months of life. The incidence of bradycardia following succinylcholine is also influenced by anaesthetic agents, being more common with halothane than isoflurane and less common after administration of thiopentone..$^{3-5}$ In addition, nitrous oxide stimulation of the sympathetic nervous system may have further reduced the incidence of bradycardia.

We are curious why McAuliffe et al., limited their study to such a small number of patients since earlier work has demonstrated that thiopentone may reduce the incidence of cardiac arrythmias following the administration of succinylcholine. ${ }^{3-5}$

Shorten et al., compared the cardiovascular effects of single dose succinylcholine administration in 24 children (6-16 yr) after pretreatment with two different doses of atropine (0.01 $\mathrm{mg} \cdot \mathrm{kg}^{-1}$ vs $\left.0.02 \mathrm{mg} \cdot \mathrm{kg}^{-1}\right) i v{ }^{6}$ Anaesthesia was induced with thiopentone, and the authors found no differences in haemodynamic variables between the groups. In particular, bradycardia did not occur in any of the 24 patients. In light of the low incidence of bradycardia reported by McAuliffe et al., it is likely that Shorten et al., did not study a large enough population to demonstrate a difference between two different doses of atropine with respect to the incidence of succinylcholineinduced bradycardia. Thus, their conclusion that it is not necessary to administer $>0.01 \mathrm{mg} \cdot \mathrm{kg}^{-1}$ of atropine before succinylcholine should be interpreted with caution.

Douglas C. Guyton MD

Steven M. Scharf Do

Department of Anesthesiology

University of Mississippi Medical Center

Jackson, MS 39216-4505

\section{REFERENCES}

1 McAuliffe $G$, Bissonnette B, Boutin $C$. Should the routine use of atropine before succinylcholine in children be reconsidered? Can J Anaesth 1995; 42: 724-9.

2 Schieber RA. Cardiovascular physiology in infants and children. In: Motoyama EK, Davis PJ (Eds.). Smith's Anesthesia for Infants and Children. St. Louis: Mosby, 1990: 77-104.

3 Schoenstadt DA, Whitcher $C E$. Observations on the mech- anism of succinylcholine-induced cardiac arrythmias. Anesthesiology 1963; 24: 358-62.

4 Williams $C H$, Deutsch S, Linde HW, Bullough JW, Dripps $R D$. Effects of intravenously administered succinylcholine on cardiac rate, rhythm, and arterial blood pressure in anesthetized man. Anesthesiology 1961;22: 947-54.

5 Badgwell JM, Cunliffe $M$, Lerman J. Thiopental attenuates dysrhythmias in children: comparison of induction regimens. Tex Med 1990; 86: 36-8.

6 Shorten GD, Bissonnette B, Hartley E, Nelson W, Carr AS. It is not necessary to administer more than $10 \mathrm{mg} \cdot \mathrm{kg}^{-1}$ of atropine to older children before succinylcholine. Can $\mathrm{J}$ Anaesth 1995; 42: 8-11.

\section{REPLY}

It is appropriate to mention that infants $<6$ mo may have parasympathetic dominance ${ }^{l}$ and explains why we chose to study children aged 1 to $12 \mathrm{yr}$.

Although, thiopentone may attenuate the incidence of dysrythmias in children, ${ }^{2}$ atropine is still administered by paediatric anaesthetists to children between one to twelve years of age before induction of anaesthesia. However, many believe that atropine in this age-group might not be necessary and this motivated this study. The most frequently used inhalational agent in our institution for induction of anaesthesia is halothane. However, in view of an increased risk of masseter muscle rigidity when succinylcholine is administered after halothane, ${ }^{3}$ thiopentone was chosen. Isoflurane might have contributed to the low incidence of arrhythmia but, this inhalational agent was not used in this study.

Although, the effect of nitrous oxide on the sympathetic nervous system activity remains controversial in adults, ${ }^{4-5}$ in infants and children, the sympathetic nervous system cannot be demonstrated. ${ }^{6}$ Previous studies reporting an increased incidence of succinylcholine-induced bradycardia in children have used nitrous oxide.

Shorten et al. ${ }^{7}$ demonstrated that $0.1 \mathrm{mg} \cdot \mathrm{kg}^{-1}$ atropine was as efficient in preventing succinylcoline-induced bradycardia as was $0.2 \mathrm{mg} \cdot \mathrm{kg}^{-1}$. In this study, vecuronium was used instead of succinylcoline because until then, the administration of succinylcoline without atropine in children was received with reluctance by the Ethics Committee at the Hospital for Sick Children.

We acknowledge that the number of patients in our study is rather small for the importance of this clinical observations. The relevance of a zero incidence of bradycardia was extensively discussed. It was also reiterated that the "true" incidence of succinylcholine-induced bradycardia in children aged one to twelve years is not clear and that the role of routine atropine administration is also unclear.

As indicated, the routine use of atropine before succinylcholine in children aged from 1 to 12 years deserves to be reconsidered, however, until true risk and benefits are established, the recommendation was that anaesthetists not change their current practice at this time whether or not this includes the routine use of atropine. The only suggestion is to continue 